\title{
A ARQUEOLOGIA DO SABER DE MICHEL FOUCAULT NO CAMPO DA COMUNICAÇÃO
}

\section{THE ARCHAEOLOGY OF KNOWLEDGE IN THE SOCIAL COMMUNICATION FIELD}

\author{
Iuri Yudi Furukita Baptista \\ Mestre em Comunicação Social pela Pontifícia Universidade Católica do Rio Grande do Sul \\ Bacharel em Comunicação Social pela Universidade Estadual de Londrina \\ E-mail: iuri.baptista@acad.pucrs.br
}

\section{RESUMO}

A arqueologia do saber formulada por Michel Foucault é aqui apresentada como uma opção metodológica para a pesquisa no campo da comunicação. Originais da história do conhecimento, as técnicas delimitadas pelo francês em A Arqueologia do saber trabalham com regularidades discursivas, funções enunciativas, formações de conceitos e definições de séries, quadros e descontinuidades. Após uma sintética introdução a seus conceitos, defende-se que a metodologia possui maleabilidade para ser aplicada em diversos estudos do campo comunicativo.

Palavras-chave: Metodologia. Comunicação em massa. Arqueologia do saber. Michel Foucault

\begin{abstract}
The Michel Foucault's archaeology is here submitted as a suitable research methodology for the social communication field. Due to its origin in knowledge's history, the techniques shaped by Foucault in The Archaeology of knowledge works with concepts such as discursive regularities, enunciate functions, concept formation and definition of sets, frames and discontinuities. After a brief description of these techniques, this paper argues that methodology has enough flexibility to be applied in a range of communicative studies.
\end{abstract}

Keywords: Metodology. Mass communication. Archaeology of knowledge. Michel Foucault

\section{INTRODUÇÃO}

O nome de Michel Foucault não é raro no campo da comunicação, embora seja tradicional das disciplinas históricas e sociais. Em meio aos comunicólogos, Foucault fica à vontade na posição de referência teórica para aqueles que estudam o poder coercitivo exercido 
pelas instituições sociais (por ele batizadas de) disciplinares. A genealogia do poder realizada pelo francês concede à comunicação enquanto transmissão de saberes um papel capital na manutenção da sociedade, abrindo a possibilidade, assim, para que a pesquisa comunicativa se aproprie de seus conceitos de corpo, biopoder, panóptico, genealogia, entre outros (FERRAZ, 2005).

Contudo, antes de se debruçar sobre a questão do poder na sociedade, Michel Foucault publicou quatro livros: Doença Mental e Psicologia [1954] ${ }^{1}$; História da Loucura na Idade Clássica [1961]; Nascimento da clínica [1963] e A palavra e as coisas [1966]. Essa "primeira fase" de Foucault ${ }^{2}$ surge muito relacionada à sua formação em psicologia e psicopatologia, tanto o é que História da loucura advém de sua tese de doutorado na Sorbonne. Com o tempo, o enfoque nos conhecimentos das ciências humanas se aprofunda e põe definitivamente de lado a psicopatologia em A palavra e as coisas, um estudo arqueológico da ciência estruturalista (DREYFUS; RABINOW, 2010).

As três primeiras publicações não tiveram ampla repercussão quando se compara com a projeção que a última pesquisa ofereceu ao pensador. Com A palavra e as coisas circulando pelo meio acadêmico francês, Foucault foi destino de repreensões, questionamentos e elogios, fazendo-o perceber a necessidade de publicar um "manual" que justificasse e formalizasse as concepções epistemológicas e metodológicas utilizadas em seus estudos (MACHADO, 2006, p.143). É nesse contexto que publica A arqueologia do saber [1969], um “manifesto" de uma nova forma de encarar a pesquisa histórica.

Estas tarefas [os quatro primeiros livros] foram esboçadas em uma certa desordem, e sem que sua articulação geral fosse claramente definida. Era tempo de lhe dar coerência - ou pelo menos, de colocá-las em prática. O resultado desse exercício é esse livro. (FOUCAULT, 1986, pp.17-18)

Clifford Geertz explica que a obra "contém, na sua maior parte, negativas quanto a posições que ele não assume, mas das quais considera ter sido acusado pelos 'comediantes e acrobatas' da vida intelectual" (in DREYFUS; RABINOW, 2010, XVI). Uma das críticas recorrentes é a inconstância das técnicas e posicionamentos tomados pelo filósofo ao longo de sua trajetória. É com finalidade de responder a essas considerações que ele escreve uma de suas frases emblemáticas: "Não me pergunte quem sou e não me diga para permanecer o mesmo." (FOUCAULT, 1986, p.20)

Uma vez mutável, ensaística e, às vezes, incoerente, ele hesita em denominar a arqueologia uma "metodologia" ou "teoria" (FOUCAULT, 1996, p.17). Este trabalho não é a retomada e a descrição exata do que se pode ler em Histoire de la Folie, Naissance de la Clinique ou Les Mots et les Choses. Em muitos pontos, ele é diferente, permitindo também diversas 
correlações e críticas internas. (ibid., p.19). Contudo, não é a ausência de rigidez que faz Foucault buscar novas formas de examinar a realidade em suas próximas obras. Buscando uma maior capacidade interpretativa para perseguir seu interesse no regimento dos sistemas sociais, o francês utiliza o domínio das unidades de discurso fornecido pela arqueologia como base para se absorver em outro conceito essencial: o poder. Suas publicações a seguir deixam de tratar da história dos saberes e encaram problemas quanto à dominação, à disciplina e à vigília. Isso não significa que a arqueologia tenha sido rejeitada.

Mesmo que Foucault considere a arqueologia insuficiente, ele não a descarta enquanto metodologia. O que de fato faz, é partir da genealogia de Friedrich Nietzsche e desenvolver outro programa de ação: a "arqueogenealogia" (ARAÚJO, 2009) ou "analítica interpretativa" (DREYFUS; RABINOW, 2010).

Foucault abandona somente a tentativa de elaborar uma teoria das regras que regem os sistemas de práticas discursivas. Como uma técnica, a arqueologia serve para isolar discursos-objetos, ela serve para distanciar e desfamiliarizar os discursos sérios das ciências humanas. Isso, por sua vez, permite a Foucault levantar as questões genealógicas. Como são esses discursos utilizados? Que papel eles representam na sociedade? (ibid., p. XXV)

Se ainda assim existir uma necessidade de defender a relevância da metodologia arqueológica, poderia se destacar que "não há (ou pelo menos não se pode admitir para a descrição histórica cuja possibilidade aqui traçamos) uma espécie de discurso ideal, ao mesmo tempo último e intemporal" (FOUCAULT, 1986, p.77). Ou seja, a arqueologia não pretende, nem considera possível, um estudo histórico capaz de esgotar todas as questões, todos os eventos, todos os discursos existentes na realidade pretérita.

Dessa forma, a arqueologia surge na qualidade de "maneiras reguladas (e descritíveis como tais) de utilizar possibilidades de discursos" (ibid., pp.76-77). A diferença que Edgar Morin faz entre método e metodologia, embora os autores tenham contexto e escolas de pensamento diversos, ajuda a compreender de que forma a arqueologia pode servir como metodologia: "As metodologias são guias a priori que programam as pesquisas, enquanto que o método derivado do nosso percurso será uma ajuda à estratégia." (MORIN, 1999, p. 39)

Isto estabelecido, as limitações da arqueologia só a fortalece, tornando-a um modelo possível de entendimento da realidade, sem propostas herméticas, sem pretensões à irrefutabilidade. Esse trabalho se presta a apresentar brevemente as propostas epistemológicas e técnicas de pesquisa descritas por Michel Foucault no livro A arqueologia do saber; para, enfim, oferecer propostas de sua utilização enquanto ferramenta metodológica nos estudos da área comunicativa, uma vez que a história do saber e os estudos comunicativos trabalham com um mesmo objeto: o documento. 


\section{AS PROPOSTAS ARQUEOLÓGICAS}

A arqueologia do saber solidifica um deslocamento progressivo entre duas propostas epistemológicas da história das ciências dos saberes, dicotomia a qual Foucault refere-se simplificadamente como "análise tradicional" e "análise atual". Ele principia suas diferenciações na maior capacidade da segunda em perceber detalhes históricos cotidianos, ou mais especificamente, temas que eram relegados às adjacências de assuntos considerados centrais pela primeira metodologia. Não obstante, possuem a aptidão de ter igual ou maior valor na busca de respostas aos problemas propostos.

Por trás da história desordenada dos governos, das guerras e da fome, desenham-se histórias, quase imóveis ao olhar - histórias com um suave declive: história dos caminhos marítimos, história do trigo ou das minas de ouro, história da seca e da irrigação, história da rotação das culturas, história do equilíbrio obtido pela espécie humana entre a fome e a proliferação. (FOUCAULT, 1986, p.03)

A questão central, porém, entre a análise histórica "tradicional" e a "atual" está na conduta da formação de sentido histórico. Se os historiadores buscavam apagar as rupturas, interrupções e intervalos para criar narrativas uniformes e sequências que fundamentassem uma corrente causal de acontecimentos; agora se debruçam no inverso, na formação de limiares, de intervenções, de disparidades que sejam capazes de estabelecer uma cronologia serial dos eventos históricos. O intuito agora é distinguir unidades.

As velhas questões da análise tradicional (que ligação ${ }^{3}$ estabelecer entre acontecimentos díspares? Como estabelecer entre eles uma sequência necessária? Que continuidade os atravessa ou que significação de conjunto acabamos por formar? Pode-se definir uma totalidade ou é preciso limitar-se a reconstituir encadeamentos?) são substituídas, de agora em diante, por interrogações de outro tipo: que estratos é preciso isolar uns dos outros? Que tipos de séries instaurar? Que critérios de periodização adotar para cada uma delas? (ibid., p.04)

Os grifos nossos destacam: há a substituição dos substantivos que indicam sequencialidade - "ligação", "sequência", "continuidade", "conjunto" e "totalidade" - por substantivos que denotam criação de unidades - "estratos", "séries", "periodização". Não se trata de novos problemas ou de uma nova disciplina, explica Foucault. As duas formas de descrição histórica possuem intersecções, tratam do mesmo objeto, colocam muitas questões idênticas, mas se valem de abordagens diferentes. Ambas formam unidades e relações, mas com intencionalidades, quantidades e qualidades diferentes.

Segundo A arqueologia do saber, as disparidades tem com epicentro o posicionamento em relação ao documento. "Nada de mal-entendidos: é claro que, desde que existe uma disciplina como a História, temo-nos servido de documentos, interrogamo-los, interrogamo-nos a seu 
respeito." (ibid., p.07) Ou seja, as verificações a cerca do documentos são, de fato, inalienáveis da disciplina histórica: há de se indagar não somente o que dizem, mas também o que pretendiam dizer; há de se questionar se tinham por vontade explicitar a verdade e que autoridade possuiriam para tal.

No entanto, a história do conhecimento alterou a forma de lidar com o documento. Se antes a tarefa primordial era constatar sua veracidade para construir uma narrativa homogênea do passado, agora busca-se trabalhá-lo em si mesmo, em seu interior: "Ela [a arqueologia] o organiza, recorta, distribui, ordena e reparte em níveis, estabelece séries, distingue o que é pertinente do que não é, identifica elementos, define unidades, descreve relações." (ibid., p.07) O tecido documental agora é decomposto em unidades, conjuntos, séries e afinidades.

Foucault concluiria que a forma tradicional de pesquisa memoriza monumentos do passado transformando-os em documentos e fazendo com que contem, "falem", aquilo que aconteceu no passado. Porém, ele rebate, estes rastros "raramente são verbais, ou dizem em silêncio coisa diversa do que dizem" (ibid., p.08). Assim, o historiador deve fazer o contrário, transformar os documentos em monumentos, de onde surgiria a analogia com o trabalho arqueológico:

Havia um tempo em que a arqueologia, como disciplina dos monumentos mudos, dos rastros inertes, dos objetos sem contexto e das coisas deixadas pelo passado, se voltava para a história e só tomava sentido pelo restabelecimento de um discurso histórico; poderíamos dizer, jogando um pouco com as palavras, que a história em nossos dias, se volta para a arqueologia - para a descrição intrínseca do monumento.” (ibid., p.08)

A nova proposta de estudos possui quatro consequências:

As noções de progresso, continuidade, causalidade, teleologia e evolução da racionalidade, do conhecimento, do pensamento ou da consciência humana são suspensas para averiguação.

A descontinuidade inverte de valor. De falha a ser suprimida, ela torna-se a validação da análise histórica. A descontinuidade contém três características: a dependência ao sujeito, pois é uma operação deliberada do historiador, e não algo inerente ao objeto estudado; a impossibilidade de ser suprimida ou relegada ao segundo plano na descrição histórica; a necessidade de seu entendimento completo, não apenas como um evento pontual entre duas positividades contínuas.

Uma vez questionada a totalização dos acontecimentos em uma "história global", pode-se esboçar o que Foucault chama de "história geral". Sem a pretensão de desenhar um "sistema de relações homogêneas" (ibid., p.11), a nova história também 
não tem pretensão de apresentar apenas elementos unitários, justapostos, independentes de sua existência coletiva. "O problema que se apresenta-e que define a tarefa de uma história geral - é determinar que forma de relação pode ser legitimamente descrita entre essas diferentes séries; que sistema vertical podem formar." (ibid., pp.11-12)

> Com o foco em constituir unidades, séries e séries verticais de séries (que Foucault denomina "quadros"), o problema é fixar-lhes os limites, formular critérios. As questões metodológicas da arqueologia são:

A constituição de um corpus coerentes e homogêneos de documentos [...]; o estabelecimento de um princípio de escolha [...]; a definição do nível de análise e dos elementos que lhe são pertinentes [...]; a especificação de um método de análise [...]; a delimitação dos conjuntos e dos subconjuntos que articulam o material estudado [...]; e a determinação das relações que permitem caracterizar um conjunto [...]. (ibid., pp.12-13)

Para o autor d'A arqueologia do saber, a nova proposta de análise é benéfica aos estudos das ciências humanas por considerar a concepção de uma história contínua um artifício instituído "como garantia de que tudo que lhe escapou poderá ser devolvido" (ibid., p.14) A supressão da descontinuidade nas descrições serve de abrigo a tudo aquilo que é conservado à distância no decorrer do tempo e promete domínio dos acontecimentos por meio de uma forçada solidez da consciência histórica. Em uma frase: Foucault lamenta e busca a superação do uso ideológico da história (ibid., p.17).

\section{AS TÉCNICAS ARQUEOLÓGICAS}

A primeira tarefa de um arqueólogo do saber é negativa: "libertar-se de todo um jogo de noções que diversificam, cada um à sua maneira, o tema da continuidade." (FOUCAULT, 1986, p.23) Em exemplo, faz-se necessário a supressão de noções como tradição, influência, evolução e espírito de época; suportes técnicos que não raramente são "demasiado mágico para poder ser bem analisado" (ibid., p.24), esquivando-se de uma delimitação rigorosa ou teórica por trás de forças etéreas tais quais andamento causal, semelhança ou repetição.

Foucault vai ainda mais longe e propõe a libertação de unidades aparentemente intocáveis: "[...] as unidades que é preciso deixar em suspenso são as que se impõem da maneira mais imediata: as do livro e da obra. [...] Não são elas apresentadas da maneira mais exata possível?" (ibid., p.25) Ele responde que não, a unidade de um livro é também subjetiva. Pensando em volumes de diversos tomos, escritos ao longo de décadas; ou antologias de poemas, entrevista, artigos avulsos; continuam necessariamente precisas? Mais do que isso: 
É que as margens de um livro jamais são nítidas nem rigorosamente determinadas: além do título, das primeiras linhas e do ponto final, além de uma configuração interna e da forma que lhe dá autonomia, ele está preso em um sistema de remissões a outros livros, outros textos, outras frases: nó em uma rede. (ibid., p.26)

E o que seria uma obra, pergunta Foucault, "uma soma de textos que pode ser denotados pelo signo de um nome próprio?” (ibid., p.26) Já de imediato surge a dúvida quanto aos pseudônimos. Então, ela se amplia aos rascunhos deixados de lado, as conversas relatadas, as cartas pessoais, uma lista de compras para o mercado. E as traduções, como ficam? Ele conclui: “A obra não pode ser considerada como unidade imediata, nem como unidade certa, nem como unidade homogênea." (ibid., p.27)

Uma vez desalojadas de seus antigos contornos, as unidades do discurso ressurgem amorfas enquanto uma população de acontecimentos dispersos. Volta-se à configuração original em que se encontra apenas um conjunto de todos os enunciados efetivos falados ou escritos. "Trata-se de um domínio imenso", admite Foucault, "mas que [ao menos] se pode definir" (ibid., p.30). Com a suspensão das formações tradicionais, tem-se a possibilidade descrever outras (ou as mesmas) unidades, contudo, e esse é objetivo, diante de um conjunto de decisões justificadas, conscientes e controladas.

Se até agora o arqueólogo apenas limpou o terreno, expurgando-o de todas as interferências externas ao documento/monumento, a primeira atitude positiva ao corpus será circunscrevê-lo. Como delimitar a região de análise discursiva, ou, em um conceito, qual é o objeto de estudo? Embora tenha afinidade com a disciplina da história das ciências humanas, a arqueologia não tem por objeto os discursos científicos, mas sim, um conceito mais amplo: campos do saber, "o espaço em que o sujeito [enunciativo] pode tomar posição para falar dos objetos que se ocupa em seu discurso" (ibid., p.206).

"O campo do saber é ao mesmo tempo teórico e prático; descritivo e institucional; analítico e regulamentar; pode ser composto por decisões, afirmações, decretos." (ARAÚJO, 2009, p.20) Oras, se Foucault se desfez de todas as unidades prévias, evidentemente evitaria o uso de conceitos já existentes como ciência, teoria ou ideologia. Dessa forma, A definição dos territórios arqueológicos é distinta da dos domínios científicos e seu entendimento prescinde de dois conceitos: a função enunciativa e a formação discursiva.

A definição de enunciado é essencial para a arqueologia do saber, pois ele é a unidade básica descrita no trabalho histórico. Contudo, diante de diversas tentativas de conceituá-lo, Foucault chega à conclusão de que "o enunciado não é, pois, uma estrutura (isto é, um conjunto de relações entre elementos variáveis, autorizando assim um número talvez infinito de modelos concretos)" (FOUCAULT, 1986, p.98). Não discernível enquanto unidade, a existência de um enunciado reside em sua função, em seu papel, em um conjunto de signos. 
Dentre as características da função enunciativa, estão: um enunciado não é uma correlação significante-significado, mas uma singularidade semântica; por isso, ele é um referencial, um contexto, um espectro de possibilidades que depende de relações com outros enunciados: "a função enunciativa não pode se exercer sema existência de um domínio associado" (ibid., p.109); o sujeito do enunciado não é o enunciador, mas o espaço em que esse enunciador pode estar presente ou ausente; por fim, possuem função enunciativa somente os elementos linguísticos que possuem existência material.

O enunciado é ao mesmo tempo e paradoxalmente repetível e estritamente relacionado ao espaço-tempo, pois é “demasiado repetível para ser inteiramente solidário com as coordenadas espaço-temporais de seu nascimento [...], demasiado ligado ao que o envolve e o suporta para ser tão livre quanto uma pura forma...” (ibid., p.120). É nesse terreno movediço que Foucault coloca as fundações da formação discursiva, entende-se por discurso um conjunto sequencial e enunciativo de signos.

Já as condições necessárias para um enunciado fazer parte de certa formação discursiva serão denominadas regras de formação. A diferença capital entre os objetos tradicionais e o objeto da metodologia de Foucault é a conciliação da dispersão como fator de coesão no conjunto de enunciados. Ou seja, o que é comum e o que é incomum formam a identidade dos objetos, são igualmente regras de formação. E de que forma se formariam as regras? Segundo Foucault, se deve

não mais tratar os discursos como conjuntos de signos [...], mas como práticas que formam sistematicamente os objetos de que falam. Certamente os discursos são feitos de signos; mas o que fazem é mais que utilizar esses signos para designar coisas. É esse mais que os torna irredutíveis à língua e ao ato da fala. É esse 'mais' que é preciso fazer aparecer e que é preciso descrever. (FOUCAULT, 1986, p.56)

Essa diretiva parte da percepção de que os objetos são resultado das práticas discursivas dos próprios enunciadores daquela formação discursiva. Por exemplo, Foucault possui como objeto a loucura na idade clássica, naturalmente, em História da loucura: na idade clássica. Mas quem define o que é a loucura na idade clássica e quem discursa sobre o tema são os próprios enunciados estudados. O uso dos signos no discurso fazem mais do que designar coisas, o uso dos signos possui um papel positivista, criando e solidificando a delimitação do objeto.

Fica claro que as relações discursivas não são intrínsecas ao objeto, contudo, tampouco são exteriores à formação discursiva. "Elas estão, de alguma maneira, no limite do discurso: oferecem-lhe objetos de que ele pode falar..." (ibid., p.52) Por isso a delimitação espaço-temporal dos documentos analisados se faz indispensável, pois os delineamentos dos saberes são sensíveis ao contexto. Essas configurações localizadas do conhecimento tangenciam o que Foucault conceitua episteme. 
Por episteme entende-se, na verdade, o conjunto das relações que podem unir, em uma dada época, as práticas discursivas que dão lugar a figuras epistemológicas, a ciências, eventualmente a sistemas formalizados. [...] A episteme não é uma forma de conhecimento, ou um tipo de racionalidade [...]; é o conjunto das relações que podem ser descobertas, para uma época dada, entre as ciências, quando estas são analisadas no nível das regularidades discursivas. (ibid., p.217)

A episteme possui algumas características de destaque: é um espaço inesgotável; não pretende englobar todos os conhecimentos de um espaço-tempo, pois convive com outras epistemes; não aparece e some bruscamente, é um conjunto móvel que se faz e desfaz; por fim, a episteme revela censuras, limites e coações às quais os discursos de uma determinada época estão sujeitos. Mas, ressalta-se, não é uma limitação negativa, ignorante, castradora. "É aquilo que, na positividade das práticas discursivas, torna possível a existência das figuras epistemológicas e das ciências." (ibid., p.218)

As três próximas formações possuem compreensão correlacionada à do objeto: a das enunciações, a dos conceitos e a das estratégias. A formação das modalidades enunciativas questiona quem é o sujeito discursivo: quem fala? $\mathrm{Na}$ arqueologia, não se busca sintetizar um indivíduo homogêneo, um personagem plano, mas caracterizá-lo por sua dispersão: "nos diversos status, nos diversos lugares, nas diversas posições que pode ocupar ou receber quando exerce um discurso, na descontinuidade dos planos de onde fala." (ibid., p.61)

Assim, a formação da enunciação se dá no sistema de relações ou feixe de relações especificados por uma prática discursiva. Tal qual os objetos não estão na "palavra" nem na “coisa" em si, mas na coesão da prática discursiva; o enunciador não surge "pelo recurso a um sujeito transcendental nem pelo recurso a uma subjetividade psicológica” (ibid., p.62), ele se faz na própria especificidade do processo enunciativo. Sendo que a identidade do regime unitário é igualmente composta pela coesão e pela dispersão dos elementos.

A formação de conceitos segue a mesma linha, emergindo do próprio campo discursivo (e não o contrário, o discurso surgindo dos conceitos). Dessa forma, argumenta Foucault, não se submeteria os enunciados múltiplos e singulares às formatações conceituais pré-estabelecidas. Com os conceitos surgindo a posteriori, "não é preciso relacioná-los nem ao horizonte da idealidade nem ao curso empírico das idéias" (ibid., p.70).

Por fim, a formação de estratégias podem ser pontuadas com exemplos enumerativos do que são estratégias: "tema, na gramática do século XVIII, de uma língua originária de que todas as outras derivariam e manteriam a lembrança por vezes decifrável; [...] teoria, entre os fisiocratas, de uma circulação das riquezas a partir da produção agrícola.” (ibid, p.71) O problema que sobressai em relação à formação das estratégias é acerca de sua distribuição na história dos saberes: serão determinadas ou aleatórias? 
Para Foucault, as formações de estratégias são uma mistura das duas alternativas. Enquanto de origens dispersas, sem relações diretas ou inevitabilidade de surgimento, também respondem a uma conjuntura indissociável ao seu tempo e espaço. Elas não possuem causalidades diretas, contudo, possuem condicionais indiretos. Deixando de ser tanto um "projeto fundamental”, quanto um “jogo secundário de opiniões [que formaram o conjunto].” (ibid., p.77)

Enfim, ao fugir das unidades tradicionais da história do saber, a arqueologia origina uma "bizarra maquinaria" que se vale de funções enunciativas e formações de discurso como metodologia nem normalizadora-estruturalista, nem interpretativa-hermenêutica. Sem pretender criar juízos de valores aos discursos históricos, trata-se de uma forma voluntária, consciente e sistemática de se reestruturar aquilo que está documentado. A arqueologia "não é nada além e nada diferente de uma reescrita" (ibid., p.160).

\section{A ARQUEOLOGIA NO CAMPO DA COMUNICAÇÃO}

Mesmo surgindo desajeitada e pontuada por conflitos juvenis, a arqueologia do saber amadurece e se consolida no papel de alicerce para todos os próximos trabalhos de Foucault devido ao seu caráter explorador-descritor. Já em Vigiar e punir [1975], o primeiro livro após $A$ arqueologia do saber, a metodologia arqueológica cria termos-chaves como "governo", "regulamentação", "transformação", “elemento", "regra”, "séries”, “externalidade”, "sistemas", sem os quais a arqueogenealogia ou analítica interpretativa ficaria insuficientemente fundamentada.

Diante disso, Hubert Dreyfus e Paul Rabinow (2010) mostram que Foucault carrega elementos estruturalistas e interpretativos ao mesmo tempo em que rejeita tanto o estruturalismo, quanto a hermenêutica. Novamente para Clifford Geertz:

\footnotetext{
Michel Foucault irrompeu no cenário intelectual no início dos anos 1960 com a sua História da loucura, uma não convencional, mas ainda razoavelmente reconhecível história da experiência ocidental da loucura. Ele se tornou, a partir daqueles anos, uma espécie de objeto impossível: um historiador não histórico, um cientista humano anti-humanista e um estruturalista contraestruturalista. (in DREYFUS; RABINOW, 2010, p.XVI)
}

E é por essa característica singular que aqui se faz uma ação positiva para propor a aplicação da arqueologia no campo da comunicação de massa, embora ela possua por objeto original "essas disciplinas tão incertas de suas fronteiras, tão indecisas em seu conteúdo, que se chamam história das idéias, ou do pensamento, ou das ciências ou dos conhecimentos" (FOUCAULT, 1986, p.23). Se não como método ${ }^{4}$, a arqueologia possui versatilidade para complementar as ferramentas metodológicas da área comunicativa. 
Mas que semelhança entre os dois campos do conhecimento permite essa transposição? Acreditamos que, da mesma maneira que a história dos saberes tem por objeto cânone o documento, as pesquisas na área de comunicação em massa também se concentram no estudo $a$ posteriori daquilo que foi impresso, veiculado, exibido, transmitido, comunicado, enfim, documentado. Se a arqueologia se difere da metodologia histórica tradicional por tornar o documento um monumento, será essa mesma ação que deverá caracterizar a arqueologia em seu novo território.

As questões que se colocam agora são: em que situações essa metodologia é adequada às pesquisas comunicativas e de que forma aplicá-las? Primeiramente, enxergamos espaço para as técnicas arqueológicas enquanto propostas descritivas e geradoras de novas unidades documentais tanto em análises de conteúdo midiático, análises de discurso midiático, análises de mídia ${ }^{5}$ e, evidentemente, na própria história das teorias da comunicação de massa.

Por exemplo, o pesquisador da história das teorias da comunicação em massa trataria de primeiramente suspender de todas as unidades usualmente utilizadas: comunicação, massa, mídia, teoria, teóricos, estudo, pesquisa, escolas, “espíritos” espaço-temporais, afinidades entre teóricos, propostas epistemológicas e até mesmo dos conceitos de texto, livro e obra. Somente em seguida, inicia as atividades conscientemente positivas de delimitação do terreno arqueológico, de busca das funções enunciativas, das formações de regras discursivas, da identificação de séries e quadros.

O mesmo se daria ao realizar um estudo de mídia, uma análise de discurso, uma interpretação de obra audiovisual ou leitura de um discurso fotográfico. Em outro exemplo, ao analisar a cobertura de determinado evento em determinados veículos midiáticos, um pesquisador que utilize os procedimentos de Michel Foucault reestruturaria todas as unidades já pré-estabelecidas dos e nos discursos: acontecimento, valores de noticiabilidade, fonte, sujeito enunciativo, lead, objeto, estratégias discursivas, funções enunciativas, inclusive de texto, reportagem e veículo.

Em resumo, pode-se afirmar que a arqueologia descontrói os arquétipos tradicionais para reconhecer, descrever e objetivar os monumentos; dando subsídios para que, posteriormente, a genealogia gere sentido, interprete e subjetive esses elementos. Uma vez que as formações discursivas não são intrínsecas, nem extrínsecas ao objeto, a ação de desconstrução-reconstrução permite que elas surjam da singularidade do encontro entre os sujeitos enunciadores do documento e o sujeito historiador.

Em uma analogia descompromissada, o labor de tornar o documento um monumento equivale a lapidar o diamante bruto em polido, pois a pedra final é a coincidência da atividade positiva do joalheiro e as características internas da pedra (seus contornos, seus veios, suas 
descontinuidades). Já a metodologia histórica tradicional, seria análoga à fundição de metais preciosos. O ouro, por exemplo, é tido como matéria contínua, assim, considera-se apropriado fundi-lo para encaixá-lo em moldes pré-definidos, lineares e homogêneos.

Visto a área da comunicação requerer tradicionalmente o estudo de documentos (sejam produtos midiáticos ou formações discursivas teóricas), as técnicas desenvolvidas em $A$ arqueologia do saber parecem apropriadas para ingressar à caixa de ferramentas metodológicas da comunicação. Pelo lado da comunicação, os interesses seriam os de dissolver relações de continuidade artificiais, reavaliar as unidades inquestionadas, enfatizar descontinuidades e descrever internamente documentos, sempre expondo publicamente as regras metodológicas e epistemológicas utilizadas.

\section{NOTAS}

1 Nesse trabalho, as datações entre colchetes demarcam o ano da primeira edição da obra e as datações entre parênteses indicam a edição listada nas referências bibliográficas.

2 Para um estudo completo do caminho percorrido pelo pensamento de Foucault, recomenda-se a leitura de Michel Foucault: uma trajetória filosófica (DREYFUS; RABINOW, 2010). A obra teve revisões e colaborações do próprio Foucault, que a considerou "uma análise clara e inteligente do trabalho que tentei fazer".

3 Grifos do original.

4 Os termos método e metodologia são utilizados nas definições de Edgar Morin, citadas na página 04.

5 Desde 2006, pesquisadores como Siegfried Zielinski, Eric Kluitenberg, Erkki Huhtamo e Jussi Parikka aplicam propostas heterogêneas do que chamam arqueologia midiática, mas a tomam no sentido de uma análise do progresso técnico dos meios de comunicação massa.

\section{REFERÊNCIAS:}

ARAÚJO, Inês Lacerda. Foucault, formação de saber, o poder disciplinar e o biopoder enquanto noções revolucionárias. Rio de Janeiro: Revista Ítaca (UFRJ), nº14, pp. 11-29, 2009.

DREYFUS, Hubert; RABINOW, Paul. Michel Foucault: uma trajetória filosófica: para além do estruturalismo e da hermenêutica. Rio de Janeiro: Forense-Universitária, 2010.

FERRAZ, Maria Cristina Franco. Contribuições do pensamento de Michel Foucault para a Comunicação. São Paulo: Revista brasileira de ciências da comunicação (Intercom), Vol. XXVIII, nº2, 2005.

FOUCAULT, Michel. A arqueologia do saber. Rio de Janeiro: Forense Universitária, 1986.

Entrevista com Michel Foucault por Sérgio Paulo Rouanet e José Guilherme Melchior. In: O homem e o discurso. Rio de Janeiro: Tempo Brasileiro, 1996. 
. O nascimento da clínica. Rio de Janeiro: Forense Universitária, 1998. fontes, 1999.

As palavras e as coisas: uma arqueologia das ciências humanas. São Paulo: Martins . Vigiar e punir: nascimento da prisão. Petrópolis: Vozes, 2004.

. História da loucura: na idade clássica. São Paulo: Perspectiva, 2011.

MACHADO, Roberto. Foucault, a ciência e o saber. Rio de Janeiro: Jorge Zahar, 2006.

MORIN, Edgar. O Método. Porto Alegre, Sulina, 1999-2005 (seis volumes). 